\title{
Analyzing the Effect of 25-Hydroxy Vitamin D Level on Strength and Endurance in Male Wrestlers
}

\author{
Selin Baikoglu ${ }^{1}$ \\ ${ }^{1}$ Istanbul University-Cerrahpaşa, The Department of Sports and Health Sciences, Turkey \\ Correspondence: Selin Baikoglu, Faculty of Sport Sciences, Istanbul University-Cerrahpasa, Avc1lar St. 34320, \\ Istanbul, Turkey. E-mail: selinbaikoglu@gmail.com
}

Received: November 27, 2019

Accepted: December 29, 2019

Online Published: January 18, 2020

doi:10.5539/jel.v9n1p237

URL: https://doi.org/10.5539/jel.v9n1p237

\begin{abstract}
$90-95 \%$ of vitamin D which has the supreme function of regulating many metabolisms in tissues and organs, is taken from the sunlight through skin. Since wrestling is performed in sun-protected sports halls, we think that a vitamin D replacement will improve the performance of wrestlers, especially as the limited exposure to sunlight is compared to outdoor sports branches. The aim of our study is to increase the strength and endurance of male wrestlers by applying 25-Hydroxy vitamin D replacement together with general and wrestling-specific trainings for 8 weeks.

36 wrestlers participated in the study and were divided into two groups as subject and control groups. Group A (n: 18) was the exercise-subject group with a 25 -hydroxy vitamin D replacement and group B (n: 18) was the exercise-control group without the vitamin D replacement applied. In the subject group, Devit-3 oral ampoule $1 \mathrm{ml}$ (300,000 I.U.) replacement was applied to the wrestlers whose 25 -hydroxy vitamin D levels were below 20 $\mathrm{ng} / \mathrm{mL}$. Wrestlers were pre-tested one week before the replacement. After 8 weeks, they were post-tested and their vitamin D levels were measured again. Wrestlers in the control group were tested at the beginning and end of the 8 -week training program without the vitamin D supplementation. In the analysis of the data, a Wilcoxon test and Mann Whitney test (one of the nonparametric tests) was used in accordance with the distribution width when the averages of the groups were evaluated in terms of significance with each other. The values that were $p<0.05$ as the significance level of the data were accepted as statistically significant and the evaluations were made accordingly.

When the results of the analysis were examined, it was seen that 25-hydroxy vitamin D levels of the wrestlers increased from $13.85 \mathrm{ng} / \mathrm{ml}$ to $26.28 \mathrm{ng} / \mathrm{ml}$ after the replacement applied to the wrestlers in the subject group. It was observed that while vitamin D levels of the group increased, their aerobic endurance decreased to $132.22 \pm$ 9.69 from $150.33 \pm 20.98(\mathrm{p}<0.05)$. Thus, their aerobic endurance improved statistically significant. No statistically significant value was obtained in the test analysis of the wrestlers in the control group.

The analysis results obtained from the study showed that the 25-hydroxy vitamin D levels in athletes increased and their aerobic capacity also increased after vitamin D induction. It is possible to say that vitamin supplementation together with 8 weeks training program is more effective for athletes to improve their strength and endurance.
\end{abstract}

Keywords: 25 -hydroxy vitamin D, wrestling, strength, aerobic endurance

\section{Introduction}

Considering athlete's health and performance, the most important benefit of vitamin D will be its effects on muscle function, bone development and on the reduction of exercise-related inflammation in individuals. From this point of view, it is understood that vitamin D levels are important for athletes to benefit from their training in the best way and to perform at the highest level. Since vitamin D deficiency may cause impaired regulation of the muscular system of athletes, it may cause injuries, stress fractures and deterioration of tendon structures in athletes (Dawson-Hughes et al., 2005). In addition, the decrease in the quality of training, disability, and prolongation of disease frequency and duration, and the corresponding decrease in athletic performance are also possible effects (Halliday et al., 2011).In order to be successful in wrestling, which is included in the fighting and salon sports, it is necessary to continue the training for a long time under very heavy training conditions. Sudden decreases in aerobic performance may occur in wrestlers who are exposed to long-term and high-intensity exercises. Various studies are being conducted to improve the performance of wrestlers. The studies on vitamin $\mathrm{D}$ and athlete 
performance have been examined carefully in the current literature and it is understood that there are studies similar to the method of our study. Bannert et al. exposed the subject group to sun light and compared $100 \mathrm{~m}$. speed test results with the control group in their study on athletes in 1991.At the end of the study, they mentioned that there was an increase in the $100 \mathrm{~m}$. performance of the subject group (Bannert et al., 1991). Investigating the relationship between vitamin $\mathrm{D}$ and strength and power tests, Ward et al. remarked that there is a direct relationship between high serum $25(\mathrm{OH}) \mathrm{D} 3$ levels and muscle strength, strength, speed and height of jump (Esslinger Fitness Indices). In this study measuring muscle strength by jumping monography, it is shown that vitamin D and muscle strength are directly proportional (Ward et al., 2009).

Since wrestling is performed in sun-protected sports halls, especially as the duration of exposure to sunlight is limited compared to other outdoor sports branches, we think that vitamin D replacement will improve the performance of wrestlers. In the light of all this information, the aim of our study is to improve the strength and endurance of male wrestlers by applying 25-Hydroxy vitamin D replacement together with general and wrestling-specific training for 8 weeks.

\section{Method}

\subsection{Participants}

Subjects were selected from wrestlers having similar structure, height, weight and age characteristics. Male wrestlers without any skeletal and muscular disorders and who have been wrestling for at least 4 years were chosen. In addition, it was ensured that the participants do not use regular medication. After evaluating all these positive and negative factors that would affect our study, the subjects of the study consisted of 36 healthy male wrestlers aged 14-16 years from two different wrestling clubs. The athletes were informed verbally in detail before the study and after reading the consent form, their parents were asked to accept and sign the form. Implementations and tests planned for the subjects were applied between 18:00 and 20:00 in the evening. The study was conducted according to the Declaration of Helsinki and was approved by the ethical committee of Istanbul University-Cerrahpaşa Medical Faculty Clinical Trials.

\subsection{Study Design}

The height and body weight of all participants were measured before the study. 36 wrestlers participating in the study were divided into two groups as subjects and control groups. Group A (n: 18) was the exercise-subject group with 25-hydroxy vitamin D replacement and group B (n: 18) was the exercise-control group with only vitamin D replacement was not applied. In our study, wrestlers participated in general and wrestling-specific training program for 6 days a week and 2 hours a day, 8 weeks in total. The trainings were applied as standard to all wrestlers by the trainers of the subject group and control group. Before starting the training program, 25-hydroxy vitamin $\mathrm{D}$ levels of the wrestlers in the subject and control groups were checked by the specialist physician through intravenous blood and the blood samples were analyzed in the appropriate hospital laboratory. Devit-3 oral ampoule $1 \mathrm{ml}(300,000$ I.U.) replacement was applied to the wrestlers in the subject group whose 25-hydroxy vitamin d level was below $20 \mathrm{ng} / \mathrm{mL}$. A pre-test was applied to the wrestlers one week before the replacement and initial values were recorded. Only the 25-hydroxy vitamin D levels of the wrestlers in the control group were measured but pre-test was applied to them without any vitamin supplementation. After the 8-week training program, the 25-hydroxy vitamin D levels of the subject group were re-measured and they were post-tested. In the control group, the athletes were re-tested regardless of their vitamin levels. Each subject group performed 15 minutes of warm-up exercises at the beginning of the training and 10 minutes of stretching exercises at the end. 


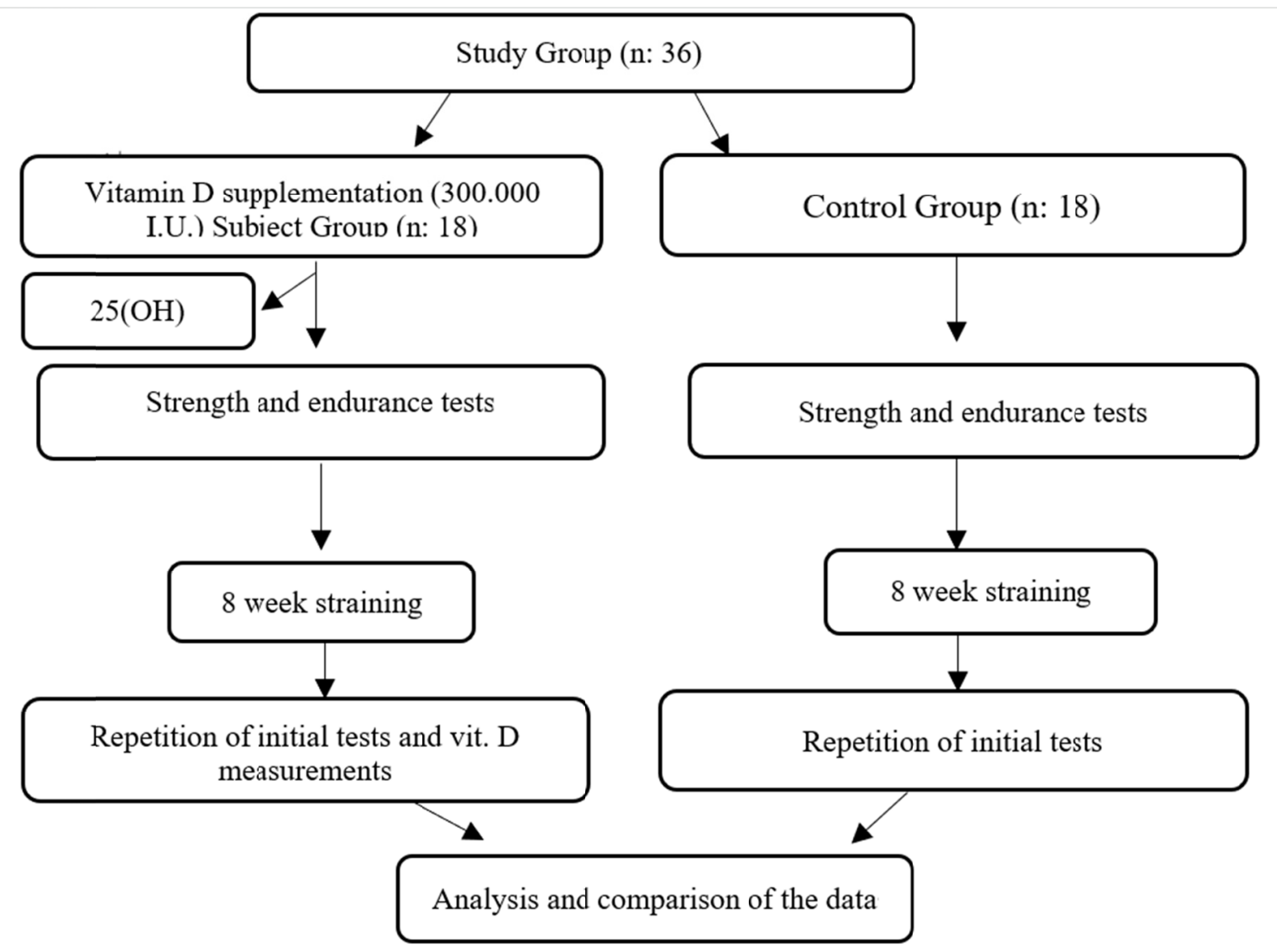

Figure 1. Overview of study design

\subsection{Test Protocol}

Wrestlers in the subject and control groups were subjected to some tests at the beginning and end of 8 weeks to measure their endurance and strength. These tests were push-up, shuttle, prone double leg lifting and 3 minutes step tests. During the push-up test aiming to measure arm strength, after taking the appropriate push-opposition, the athlete was asked to push-up until he was exhausted and every correct push-up was recorded. During the shuttle test, applied to measure the endurance of abdominal muscles, the maximum number of correct shuttles performed by athletes within 30 seconds was counted and recorded. To determine the endurance of the back and waist muscles, prone double leg lifting test was applied. During the test, the athlete was asked to life facedown, put his arms under his head and raise both legs as much as he could and the time, he could stay in this position was recorded. 3-minute step test was used to measure the aerobic endurance of the athletes. Subjects were asked to step up and down for 3 minutes to a $30.5 \mathrm{~cm}$ step with a metronome set at 96 beats $/ \mathrm{min}$. 5 seconds after the end of the test, their heart rate values were counted for 1 minute and the obtained pulse value was recorded.

\subsection{Statistical Analysis}

The data obtained after the test measurements were evaluated with SPSS 20 package program in silico. Anthropometric measurement values, push-up test, shuttle test, prone double-leg lifting test and 3-minute step test values of the subjects and control groups were recorded as variables of our study.

In the analysis of the data, Wilcoxon test and Mann Whitney test, one of the non parametric tests, was used in accordance with the distribution width when the averages of the groups were evaluated in terms of their significance with each other. The values that were $p<0.05$ as the significance level of the data were accepted as statistically significant and the evaluations were made accordingly. 


\section{Results}

Table 1. Age, height, weight and 25-hydroxy vitamin D values of the subject group

\begin{tabular}{lllll}
\hline Parameter & $\mathrm{N}$ & Minimum & Maximum & Mean \pm Sd \\
\hline Age & 18 & 14 & 16 & $15.00 \pm 1.0$ \\
Height & 18 & 1.53 & 1.75 & $1.65 \pm .07$ \\
Weight & 18 & 44.0 & 74.0 & $57.9 \pm 9.8$ \\
Dvit.-first & 18 & 8.09 & 25.06 & $13.85 \pm 4.46$ \\
Dvit-last & 18 & 17.38 & 34.56 & $26.28 \pm 4.20$ \\
\hline
\end{tabular}

Table 1 shows the evaluated 25-Hydroxy vitamin D levels together with the anthropometric in formation of the subject group. After the wrestlers' initial measurements of vitamin D, it has been seen that the average values of 25-hydroxy vitamin D levels increased from $13.85 \mathrm{ng} / \mathrm{ml}$ to $26.28 \mathrm{ng} / \mathrm{ml}$ as a result of the vitamin indication.

Table 2. Age, height, weight and vitamin D values of the control group

\begin{tabular}{lllll}
\hline Parameter & $\mathrm{N}$ & Minimum & Maximum & Mean $\pm \mathrm{Sd}$ \\
\hline Age & 18 & 14 & 16.0 & $14.78 \pm 80$ \\
Height 2 & 18 & 1.52 & 1.76 & $1.64 \pm 07$ \\
Weight 2 & 18 & 42.5 & 84.0 & $58.55 \pm 11.30$ \\
D vit. & 18 & 6.58 & 25.06 & $13.79 \pm 4.74$ \\
\hline
\end{tabular}

The anthropometric values and vitamin D levels of 18 wrestlers consisting the control group are given in Table 2 . It is noteworthy that vitamin D levels of the wrestlers are below $20 \mathrm{ng} / \mathrm{ml}$.

Table 3. Pre-test and post-test results of 18 wrestlers belonging to the subject group

\begin{tabular}{llll}
\hline Parameter & Avg. & Sd & P \\
\hline Push-up Pre-test & 26.39 & 3.96 & \\
Push-up Pretest & 27.67 & 3.79 & .155 \\
Shuttle Test Pre-test & 51.28 & 13.32 & \\
Shuttle Test Post-test & 52.11 & 13.80 & .777 \\
Hind Leg Shuttle Test Pre-test & 1.72 & .51 & \\
Hind Leg Shuttle Test Post-test & 1.63 & .45 & .586 \\
Aerobic Step Test Pre-test & 150.33 & 20.98 & \\
Aerobic Step Test Post-test & 132.22 & 9.69 & $\mathbf{. 0 0 3}$ \\
\hline
\end{tabular}

In Table 3, the strength and aerobic test results of the 18 wrestlers consisting the subject group before the replacement are compared with the test results after the replacement. The increased vitamin D level as a result of the analysis shows a statistically significant increase in 3-minute step test result which is anaerobic strength test (p $<0.05)$.

Table 4. Comparison of pre-test and post-test results of 18 wrestlers consisting the control group

\begin{tabular}{llll}
\hline Parameter & Avg. & Sd & P \\
\hline Push-up Pre-test & 27.06 & 5.64 & \\
Push-up Post-test & 26.78 & 4.76 & .656 \\
Shuttle Test Pre-test & 25.28 & 4.39 & \\
Shuttle Test Post-test & 25.89 & 4.00 & .251 \\
Hind Leg Shuttle Test Pre-test & 3.72 & 9.07 & \\
Hind Leg Shuttle Test Post-test & 1.57 & .51 & .844 \\
Aerobic Step Test Pre-test & 143.89 & 20.44 & \\
Aerobic Step Test Post-test & 133.07 & 36.11 & .035 \\
\hline
\end{tabular}

Table 4 shows the pre-test and post-test values of the test parameters of the control group. There is no statistically significant increase in any of the test results of the control group $(\mathrm{p}<0.05)$. 
Table 5. The Mann Whitney U test results of the wrestlers in experiment and control groups

\begin{tabular}{|c|c|c|c|c|c|}
\hline Parameter & Participant & $\mathrm{N}$ & Avg. & $\mathrm{Sd}$ & $\mathrm{P}$ \\
\hline \multirow{3}{*}{ Push-up Pre-test } & Experiment & 18 & 26.388 & 3.957 & .364 \\
\hline & Control & 18 & 27.055 & 5.640 & \\
\hline & Total & 36 & & & \\
\hline \multirow[t]{3}{*}{ Shuttle Test Pre-test } & Experiment & 18 & 27.666 & 3.788 & .679 \\
\hline & Control & 18 & 26.777 & 4.759 & \\
\hline & Total & 36 & & & \\
\hline \multirow{3}{*}{ Shuttle Test Post-test } & Experiment & 18 & 51.277 & 13.323 & .000 \\
\hline & Control & 18 & 25.277 & 4.389 & \\
\hline & Total & 36 & & & \\
\hline \multirow{3}{*}{ Push-up test- Post-test } & Experiment & 18 & 52.111 & 13.804 & .000 \\
\hline & Control & 18 & 25.888 & 3.998 & \\
\hline & Total & 36 & & & \\
\hline \multirow[t]{3}{*}{ Hind Leg Shuttle Test Pre-test } & Experiment & 18 & 1.720 & .511 & .248 \\
\hline & Control & 18 & 3.719 & 9.073 & \\
\hline & Total & 36 & & & \\
\hline \multirow[t]{3}{*}{ Hind Leg Shuttle Test Post-test } & Experiment & 18 & 1.628 & .454 & .558 \\
\hline & Control & 18 & 1.567 & .505 & \\
\hline & Total & 36 & & & \\
\hline \multirow[t]{3}{*}{ Aerobic Step Test- Pre-test } & Experiment & 18 & 150.333 & 20.978 & .205 \\
\hline & Control & 18 & 143.888 & 20.436 & \\
\hline & Total & 36 & & & \\
\hline \multirow[t]{3}{*}{ Aerobic Step Test- Post -test } & Experiment & 18 & 132.222 & 9.692 & .181 \\
\hline & Control & 18 & 133.073 & 36.109 & \\
\hline & Total & 36 & & & \\
\hline
\end{tabular}

Table 5 presents the Mann Whitney U test results related to pre and post tests parameters of the wrestlers in experiment and control groups. A statistically meaningful difference was found in pre-test results in the push-up parameter while no statistically meaningful difference was seen in other test parameters $(p<0.05)$

\section{Discussion}

In particular, physiological values of athletes who want to improve their performance and achieve new success, determine the quality of their training. One of the main reasons for our preference for wrestlers between the ages of 14-16 in our study is the incomplete development of their muscles and bones. In addition, another important factor in forming our subject group is that wrestling is performed in indoor sports hall and the athletes are exposed to the sun less. The fact that 25-Hydroxy vitamin D replacement to young wrestlers will improve their strength and endurance development is the hypothesis of our study.

At the beginning of our study, it was seen that measured 25-Hydroxy vitamin D levels of wrestlers in the subjects and control groups were below $20 \mathrm{ng} / \mathrm{ml}$ which was considered as the limit. Thus, Devit-3 oral ampule $1 \mathrm{ml}$ (300.000 I.U.) replacement was applied to 18 wrestlers consisting the subject group. Following the replacement, 25 -Hydroxy vitamin D levels which we measured in the first stage, were observed to increase from $13.85 \mathrm{ng} / \mathrm{ml}$ to $26.28 \mathrm{ng} / \mathrm{ml}$.

With the increase of vitamin D levels of the athletes, we compared the values obtained from the pre-test and post-test that we applied to the subject group and we examined the results. It was observed that especially their aerobic endurance decreased from $150.23 \pm 20.98$ to $132.22 \pm 9.69$ which showed that their aerobic endurance increased statistically significant. The fact that there was no significant increase in the analysis of the data we obtained from the tests we applied in order to measure the arm strength, the abdominal muscle endurance and back and waist muscle endurance is a result that needs to be emphasized.

When the results of the tests applied at the beginning and end of the 8-week training period of the control group without vitamin D replacement were compared, it was seen that there was a slight increase in the test results, but this increase was not statistically significant. From this point of view, we can conclude that the 8-week training program as well as the 25 -Hydroxy vitamin D levels of the athletes being below the desired limit $(20 \mathrm{ng} / \mathrm{ml})$, are not sufficient to improve the pre-test and post-test results of the 8-week training program as statistically significant.

Considering the data analysis on the test parameters of both groups, it was seen that before the replacement of 25-Hydroxy vitamin D, the push-up pre-test results were 51.277 in the experiment group, and it rose up to 52.111 in post-tests following the replacement during the 8-week training program. Also, the push-up pre-test results of the wrestlers in the control group rose slightly up to 25.288 from 25.277 . The difference is a statistically important 
finding. Additionally, different test parameters in the crunch pre-test and post-test results are also remarkable. To the analysis results, control group's test values were higher than the experiment group's values during 8-week training while following the 8-week training and replacement, the post-test values of the experiment group showed a higher rise compared to the control group.

As a result of the literature search, we conducted between 1991 and 2019, it has been found that there are study results which are parallel and not parallel to our study. Alimoradi et al. conducted a study similar to the results we obtained in our study. In order to examine the effect of vitamin D supplementation on sporting performance, they randomly selected 70 athletes and they divided these 70 athletes into two groups as subject and control group. The subject group received 50,000 IU vitamin D weekly and the control group did not receive any vitamin D supplementation. After the study of 8 weeks, they stated as the result of the study that weekly vitamin D supplementation caused an increase in calcifediol in the blood circulation and this increase improve the strength and speed performance of the subject group (Alimoradi et al., 2019).

Ksiazek et al. studied the relationship between paw, leg and muscle strength of elite judoists and their 25(OH) D levels. According to the findings of the study, $25(\mathrm{OH}) \mathrm{D}$ levels were found to be positively correlated with skeletal muscle strength, strength and work in elite athletes (Ksiazek et al., 2018). Ziegenfuss et al. (2015) gave nutritional supplement containing vitamin D to the subject group (n: 14) for 30 days in their study with 27 golfers. The placebo effect was investigated in the control group (n: 13). They stated that the subject group showed more successful performance compared to the placebo-influenced group after 30 days (Ziegenfuss et al., 2015).

Contrary to the results of the study mentioned above, Valtueña et al. gave 2000 IU vitamin D3 supplementation to the subject group every day for 12 weeks and examined the placebo effect in the control group. In the analysis of the data obtained before and after the supplementation, it was observed that the group receiving D3 supplementation did not show a significant difference in performance compared to the placebo group (Valtueña et al., 2014).

Seo et al. emphasized as a result of their study that $25(\mathrm{OH})$ D level did not cause a significant increase in athletic performance of adolescent athletes and it showed a weak correlation on anaerobic endurance and also it did not have a positive effect on blood borne markers (Seo et al., 2019). In their study, Maroon et al. examined the vitamin D levels of 80 professional football players before the season of 2011 and compared them with the levels in seasons of 2011-2012 and 2012-2013. Vitamin D levels were $25.6 \pm 11.3 \mathrm{ng} / \mathrm{ml}$ in black players and $37.4 \pm 8.6$ $\mathrm{ng} / \mathrm{ml}$ in white players. They reported that black players with lower vitamin D levels have higher risk of bone fractures (Maroon et al., 2015).

Bezuglov et al. reported as a result of their study that daily supplementation of 50,000 IU vitamin D in young Russian footballers was an effective and well tolerated treatment for vitamin D deficiency (Bezuglov et al., 2019). When the information obtained from our study and the different results obtained from all the studies mentioned above are evaluated together, it is not possible to say clearly that the effect of $25(\mathrm{OH}) \mathrm{D}$ level on athlete performance is positive or negative.

\section{Conclusion and Suggestions}

When we evaluated the results of our study in general, we found that 25 hydroxy vitamin D levels of all the wrestlers who participated voluntarily were below the accepted limit. After the induction of vitamin D, we obtained the results of the analysis showing that 25 -hydroxy vitamin D levels increased together with the aerobic capacity of the athletes. Based on the analysis results of our study, we can say that it is important to monitor the vitamin D levels of athletes, especially those working out in indoor sports fields protected from sun rays. In addition, it is possible to say that vitamin supplementation together with 8 weeks of the training program is more effective for athletes to improve their strength and endurance.

In future studies, it is necessary to optimize the existing treatment plans for 25-hydroxy vitamin D deficiency and to put emphasis on the research aiming to reduce the risk factors that may occur due to vitamin D deficiency. In addition, it should be kept in mind that normal levels of vitamin $\mathrm{D}$ in athletes will improve the quality of life; those interested in athletes' health must provide adequate information and approaches to this is sue.

\section{References}

Alimoradi, K., Nikooyeh, B., Ravasi, A. A., Zahedirad, M., Shariatzadeh, N., Kalayi, A., \& Neyestani, T. R. (2019). Efficacy of vitamin D supplementation in physical performance of iranian elite athletes. International Journal of Preventive Medicine, 10(1), 100. https://doi.org/10.4103/ijpvm.IJPVM_227_18

Bannert, N., Starke, I., Mohnike, K., \& Fröhner, G. (1991). Parameters of mineral metabolism in children and adolescents in athletic training. Kinderarztl Prax, 59(5), 153-156. 
https://doi.org/10.1007/978-1-4615-3678-9_15

Bezuglov, E., Tikhonova, A., Zueva, A., Khaitin, V., Waskiewicz, Z., Gerasimuk, D., ... Knechtle, A. (2019). Prevalence and treatment of vitamin D deficiency in young male russian soccer players in winter. Nutrients, 11(10), 2405. https://doi.org/10.3390/nu11102405

Dawson-Hughes, B., Heaney, R. P., Holick, M. F., Lips, P., Meunier, P. J., \& Vieth, R. (2005). Estimates of optimal vitamin D status. Osteoporos International, 16(7), 713-716. https://doi.org/10.1007/s00198-005-1867-7

Gordon, C. M., DePeter, K. C., Feldman, H. A., Grace, E., \& Emans, S. J. (2004). Prevalence of vitamin D deficiency among healthy adolescents. Arch Pediatr Adolesc Med., 158(6), 531-537. https://doi.org/10.1001/archpedi.158.6.531

Halliday, T., Peterson, N. J., Thomas, J., Kleppinger, K., Hollis, B. W., \& Larson-Meyer, D. E. (2011). Vitamin D status relative to diet, lifestyle, injury, and illness in college athletes. Medicine \& Science in Sports \& Exercise, 43(2), 335-343. https://doi.org/10.1249/MSS.0b013e3181eb9d4d

Holick, M. F., Binkley, N. C., Bischoff-Ferrari, H. A., Gordon, M. C., Hanley, D. A., Heaney, R. P., ... Weaver, C. M. (2011). Evaluation, treatment, and prevention of vitamin D deficiency: an endocrine society clinical practice guideline. J Clin Endocrinol Metab, 96(7), 1911-1930. https://doi.org/10.1210/jc.2011-0385

Ksiazek, A., Dziubek, W., Pietraszewska, J., \& Slowinska-Lisowska, M. (2018). Relationship between 25(OH)D levels and athletic performance in elite Polish judoists. Biol Sport, 35(2), 191-196.

Maroon, J. C., Mathyssek, C. M., Bost, J. W., Amos, A., Winkelman, R., Yates, A. P., ... Norwig, J. A. (2015). Vitamin D profile in national football league players. The American Journal of Sports Medicine, 43(5), 12411245. https://doi.org/10.1177/0363546514567297

Rockell, J., Green, T. J., Skeaff, C. M., Whiting, S. J., Taylor, R. W., Williams, S. M., ... Wohlers, M. W. (2005). Season and ethnicity are determinants of serum 25-hydroxyvitamin D concentrations in New Zealand children aged 5-14 y. The Journal of Nutrition, 135, 2602-2608. https://doi.org/10.1093/jn/135.11.2602

Seo, M. W., Song, J. K., Junk, H. C., Kim, J. H., \& Lee, J. M. (2019). The associations of vitamin D status with athletic performance and blood-borne markers in adolescent athletes: a cross-sectional study. International Journal of Environmental Research and Public Health, 16(18), 3422. https://doi.org/10.3390/ijerph16183422

Uçar, F., Taşlıpınar, M. Y., Soydaş, A. Ö., \& Özcan, N. (2012). Ankara Etlik İhtisas Eğitim Araştırma Hastanesi'ne başvuran hastalarda 25-oh vitamin D düzeyleri. Eur J Basic Med Sci., 2, 12-15.

Valtueña, J., Dominguez, D., Til, L., González-Gross, M., \& Drobnic, F. (2014). High prevalence of vitamin D in sufficiency among elite Spanish athletes the importance of outdoor training adaptation. Nutr Hosp, 30(1), $124-131$.

Wacker, M., \& Holick, M. F. (2013). Vitamin D-effects on skeletal and extraskeletal healt hand the need for supplementation. Nutrients, 5, 111-148. https://doi.org/10.3390/nu5010111

Ward, K. A., Das, G., Berry, J. L., Roberts, S. A., Rawer, R., Adams, J. E., \& Mughal, Z. (2009). Vitamin D status and muscle function in post-menarchal adolescent girls. The Journal of Clinical Endocrinology \& Metabolism, 94(2), 559-563. https://doi.org/10.1210/jc.2008-1284

Wharton, B., \& Bishop, N. (2003). Rickets (Review). Lancet, 362, 1389-400. https://doi.org/10.1016/S0140-6736(03)14636-3

Ziegenfuss, T. N., Habowski, S. M., Lemieux, R., Sandrock, J. E., Kedia, A. W., Kerksick, C. M., \& Lopez, H. L. (2015). Effects of a dietary supplement on golf drive distance and functional indices of golf performance. Journal of the International Society of Sports Nutrition, 12(4), 1-14. https://doi.org/10.1186/s12970-014-0065-4

\section{Copyrights}

Copyright for this article is retained by the author, with first publication rights granted to the journal.

This is an open-access article distributed under the terms and conditions of the Creative Commons Attribution license (http://creativecommons.org/licenses/by/4.0/). 